\title{
Identification of Rodlet Cells in Aquatic Bird as Egyptian Goose (Alopochen Egyptiacus): The Enteric Rodlet Cells
}

\author{
Kamal EH Abdalla', Abdelhafeez HH$^{1}{ }^{*}$, Wafaa Gaber ${ }^{1}$ and Esraa \\ Tamam $^{2}$ \\ ${ }^{1}$ Department of Anatomy, Embryology \& Histology, Assiut University, Egypt \\ ${ }^{2}$ Department of Anatomy, Sohag University, Egypt
}

\section{Research Article}

Volume 3 Issue 1

Received Date: March 05, 2019

Published Date: March 26, 2019

*Corresponding author: Hanan Hassan Abd-Elhafeez, Assistant professor of histology, Department of anatomy, embryology and histology, Faculty of veterinary medicine, Assiut University, Assiut, Egypt, 71526, Tel: +01096208824; Email: hhmmzz91@gmail.com

\section{Abstract}

Rodlet cells have been specified for Teleost's. They are unique cells has multi functions as secretion, osmoregulation, immune and sensory function. They considered as wandering cells that migrate through tissues and organs. The current study aims to investigate existence of rodlet cells in aquatic birds. The current study used the Egyptian goose (Alopochen egyptiacus) as a model of the aquatic birds. Rodlet cells were identified using semithin sectioning and Transmission electron microscopy. Different stages of rodlet cell including granular, transitional, pre-rupture and rupture stages were identified in the cecum and colon mucosa of the geese. Granular stage of rodlet cell was detected in the subepithelial lamina propria and contained granules of different sizes and shapes. Transitional rodlet cells were detected in the subepithelial lamina propria and within the epithelium. The transitional stage of rodlet cells were dominated by secretory granules of varying electron densities. The pre-ruptured stage of rodlet cells were demonstrated within the epithelium. The pre-ruptured stage of rodlet cells exhibited cell polarity with broad basal part and tapered apical end. The thick capsule and typical rodlet granules characterized this stage. Ruptured rodlet cells were detected at the surface of the enteric epithelium. The rupture stage of rodlet cells liberated their contents through the apical pores via holocrine mode of secretion. In conclusion, the current study for the first time provided an evidence for existence of the enteric rodlet cells in the aquatic bird. Future studies should consider localization of rodlet cells in different organs of aquatic birds.

Keywords: Rodlet Cells; Colon; Cecum; Egyptian Geese; Semithin; Transmission Electron Microscope 


\section{Cytology \& Histology International Journal}

\section{Introduction}

Rodlet Cells are unique type of cells. They have been specified to aquatic species either the marine or the freshwater fish [1]. Rodlet cells considered as wandering cells that capable to secrete proteolytic enzymes practically MMP-9 to migrate through tissues and organs [2]. Hence, they are found in various body systems including respiratory, digestive, genital, Integument, immune, cardiovascular, skeletal system, eye and the abdominal cavity [2-4]. Several functions have been proposed for rodlet cells. They have been implicated in ion transportation to act in osmoregulation [5] and serve in sensory function [6]. The widely assumptive theory that they function as immune cells $[7,8]$.

Different stages of rodlet cells have been identified olfactory organ of the Ruby shark. Rodlet are derived from the olfactory stroma. Rodlet progenitors have extensive vesicles that gradulally disappear and replaced by a primitive form of the rodlet granules, hence termed the granular stage. The granules develop a central rod core in transitional rodlet stage. In the mature stage, the granules acquire the typical form of rodlet granules. The mature rodlet cells have distinctive criteria including thick capsule, rod-shaped rodlet granules with a centeral dense core [2].

Rodlet cell seems to be a criterion for aquatic species. Thus, the current study aims to investigate rodlet cells in aquatic birds. The Egyptian goose (Alopochen egyptiacus) belongs to order Anseriformes and the family Anatidae, found in Africa, mostly the Nile Valley and south of the Sahara desert. We used geese as one of the aquatic birds to explore existence of rodlet cells in cecum and colon samples using semithin sections, and transmission electron microscopy (TEM).

\section{Materials and Methods}

\section{Birds}

This study was applied on a total number of five apparently healthy adult male Egyptian geese (Alopochen egyptiacus) collected from Assiut governorate. All birds were fasted for 12 hours, live body weight (about 2500 gm.) was recorded, and then all of them were slaughtered.

\section{Sampling}

Small specimens (2.0-3.0 $\mathrm{mm}$. long) from the base, body and apex of the cecum, the cranial, middle and caudal parts of the colon were obtained and washed for several times in normal saline. The specimens were fixed in Karnovsky fixative $10 \mathrm{~mL}$ paraformaldehyde 25\%, 10 mL glutaraldehyde $50 \%, 50 \mathrm{~mL}$, phosphate buffer $\mathrm{pH} 7.2$ and $30 \mathrm{~mL} \mathrm{DW}$ ) for 4 hours at $4^{\circ} \mathrm{C}$. Post fixation was made in $1 \%$ sodium tetroxide solution for two hours at $4^{\circ} \mathrm{C}$.

\section{Transmission Electron Microscopy (TEM)}

Preparations of Resin Embedding Samples: The samples were again washed in $0.1 \mathrm{M}$ phosphate buffer (pH 7.2). Samples were dehydrated in ascending graded series of ethanol. The dehydrated samples were embedded in resin (Epon-araldite). Polymerization of samples was performed by using Epon mix and accelerator (DMP30) (1.5\%). The blocks were incubated for 3 days as the following; at $60^{\circ} \mathrm{C}$ in the first day, at $70^{\circ} \mathrm{C}$ in the second day and $75^{\circ} \mathrm{C}$ in the third day.

a. Semithin sections $\left(\begin{array}{lll}1 & \mu \mathrm{m}\end{array}\right)$ were cut using an ultramicrotome Ultracut E (Reichert-Leica, Germany) and stained with toluidine blue.

b. Ultrathin sections were obtained by a Reichert ultramicrotome. The sections $(70 \mathrm{~nm})$ were stained with uranyl acetate and lead citrate [9] and examined by JEOL100CX II transmission electron microscope in the electron microscopy unit of Assiut University.

\section{Results}

The current study aimed to investigate rodlet cells and their differential stages in the cecum and colon of the geese. We used semithin sectioning and TEM for identification of rodlet cells. Different stages of rodlet cell including granular, transitional, pre-rupture and rupture stages were identified in the epithelium and lamina propria of cecum and colon mucosa of the geese. Granular stages of rodlet cell were detected in the subepithelial lamina propria (Figure 2A) which contained granules of different sizes and shapes. Transitional rodlet cells were detected in the subepithelial lamina propria (Figures 1 \& $2 \mathrm{~A}$ ) and within the epithelium (Figure 2B). The transitional stage of rodlet cells were dominated by secretory granules of varying electron densities, which represent different stages of granules maturation and matrix of grading electron densities (Figure 3). 


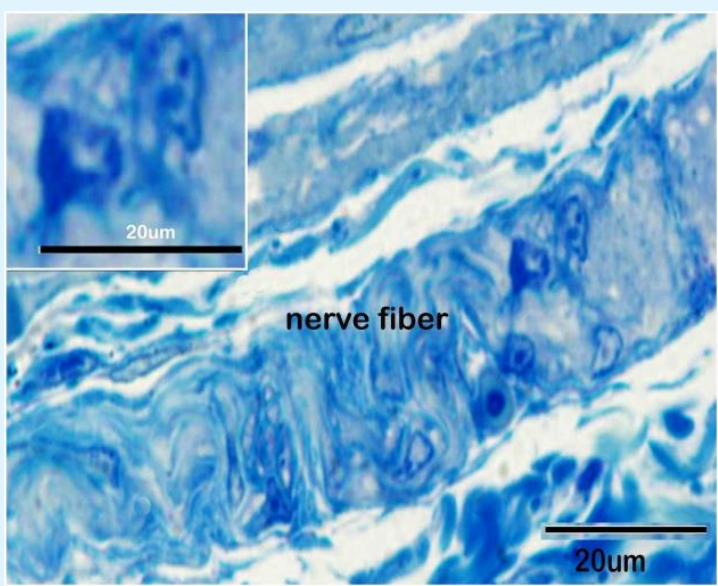

Figure 1: Photomicrographs of a semi- thin section of the apex of cecum stained by toluidine blue showing the transitional rodlet cell (black selected square) in the lamina propria around the nerve fiber.

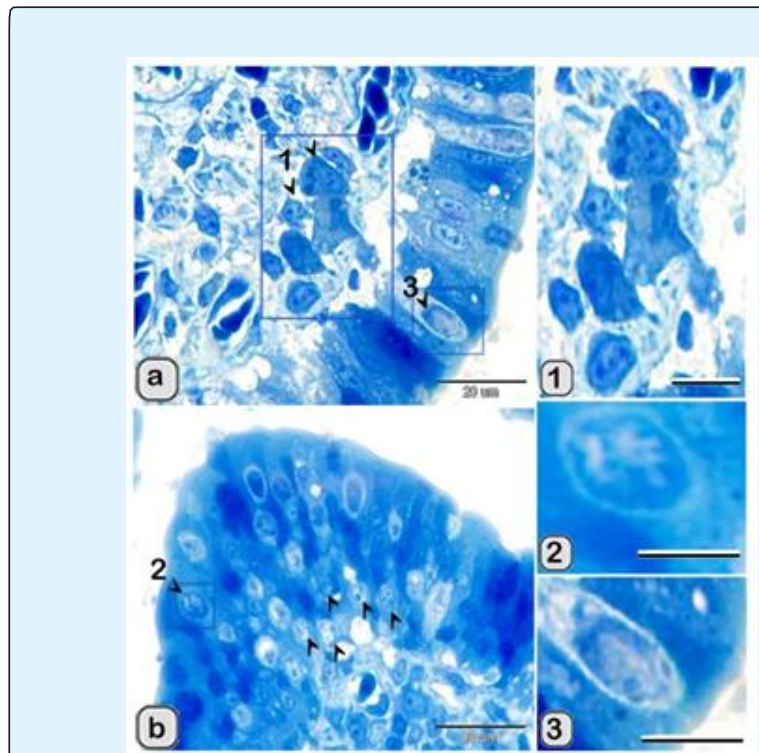

Figure 2: Photomicrographs of a semithin section of the apex of cecum stained by toluidine blue showing the localization of different stages of rodlet cells in the lamina propria and the epithelium of the geese colon 2(A) Granular stage of rodlet cell 1) which contained granules of different sizes and shapes and present in the lamina propria and prerupture stage of rodlet cell 3) which were pear shape and embedded between the lining columnar cells. (B) Transitional stage of rodlet cell 2) which contained secretory granules of different sizes and characterized by well-developed capsule. Bar= 10 micron in 1,2,3.

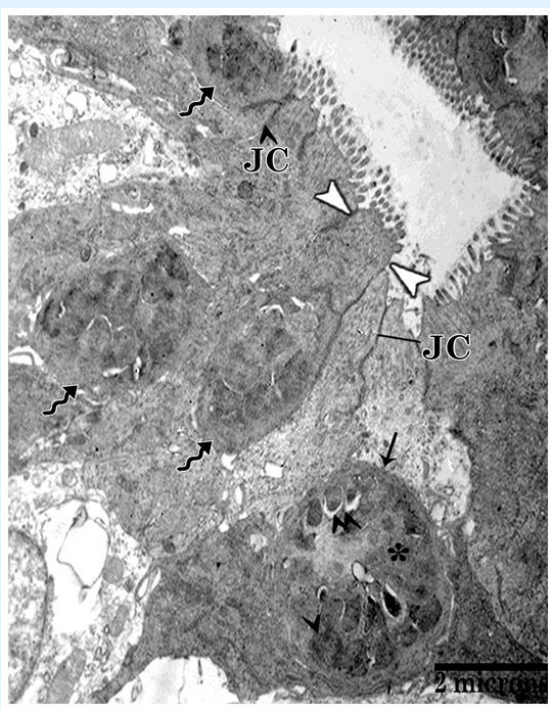

Figure 3: Transmission electron micrograph (TEM) stained by urnayl acteate and lead citrate of the apex of cecum showing the prerupture stage of rodlet cell (wavy arrows) at different levels of the epithelium and move toward the apical portion of the villi, attached to the apical part of the villi (white arrowheads), attached by junction complex (JC), covered by microvilli (Mv) and discharge it's secretion by holocrine mode of secretion (thick arrow). Transitional stage of rodlet cell $(*)$ characterized by thin capsule (black arrow), electron lucent (double arrowheads) and electron dense (single arrow heads) granules.

The pre-ruptured stage of rodlet cells were demonstrated within the epithelium (Figures 4A \& 6). The pre-ruptured stage of rodlet cells were pear in shape with widened basal part, tapered apical end, and covered by thick capsule. Almost of the cytoplasm was occupied by rodlet granules. They were demonstrated at different levels of the epithelium, move toward the apical portion of the villi, attached by junction complex, covered by microvilli, and discharge its secretion by holocrine mode of secretion (Figures 5A \& 5B). Ruptured rodlet cells were detected at the surface of the epithelium where they liberated the secretory contents (Figure 4B). The rupture stage of rodlet cells secrete their contents through the apical pores and extrude the whole contents to the epithelial surface by holocrine mode of secretion (Figure 5C). 


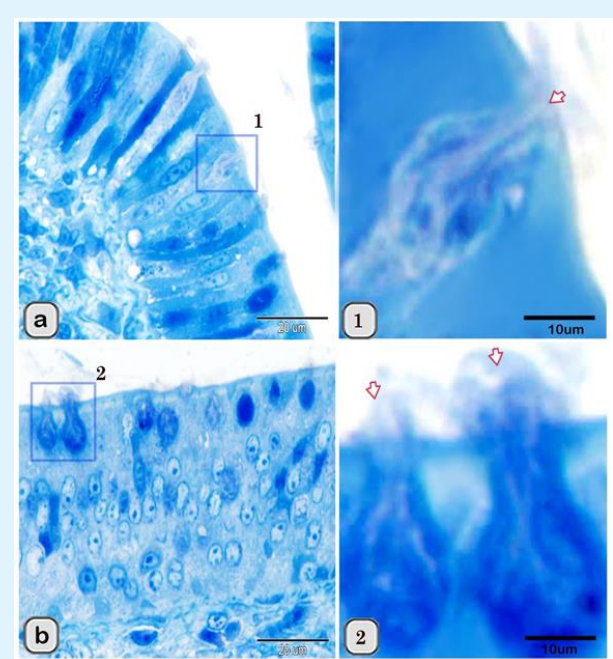

Figure 4: Photomicrographs of a semithin section of the apex of cecum stained by toluidine blue showing the the per-ruptured and ruptured rodlet cells. (A) Prerupture stage of rodlet cells 1) (black arrowhead). (B) Rupture stage of rodlet cells 2) which released its contents on the epithelial surface.

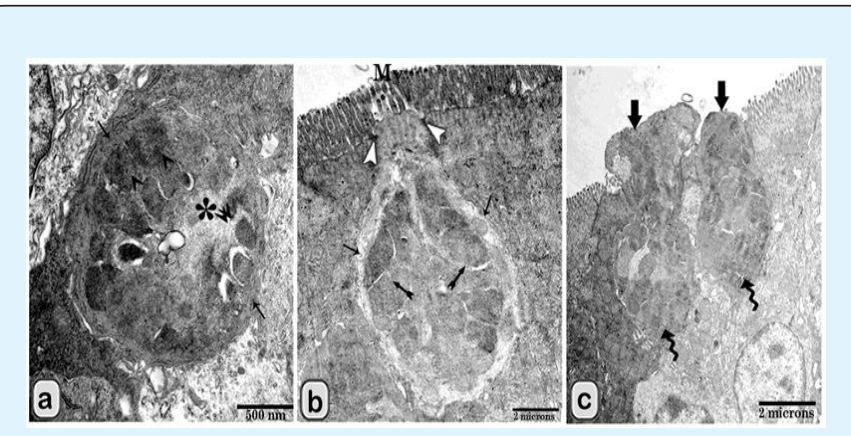

Figure 5: Transmission electron micrograph (TEM) stained by urnayl acteate and lead citrate of the apex of cecum showing the different stages of rodlet cell: (A) Transitional stage of rodlet cell $\left({ }^{*}\right)$ with thin connective tissue capsule (black arrow), electron lucent (double arrowheads) and electron dense (single arrowheads) granules. (B) zPrerupture stage of rodlet cell which were pear shape characterized by very thick capsule (black arrow), secretory granules (tailed arrows), attached to the apical part of the villi (white arrowheads) and covered by microvilli (Mv). (C) Rupture stage of rodlet cell (wavy arrows) which was completely released its secretion by holocrine mode (thick arrows).
Kamal EH Abdalla, et al. Identification of Rodlet Cells in Aquatic Bird as Egyptian Goose (Alopochen Egyptiacus): The Enteric Rodlet Cells. Cytol Histol Int J 2019, 3(1): 000108.

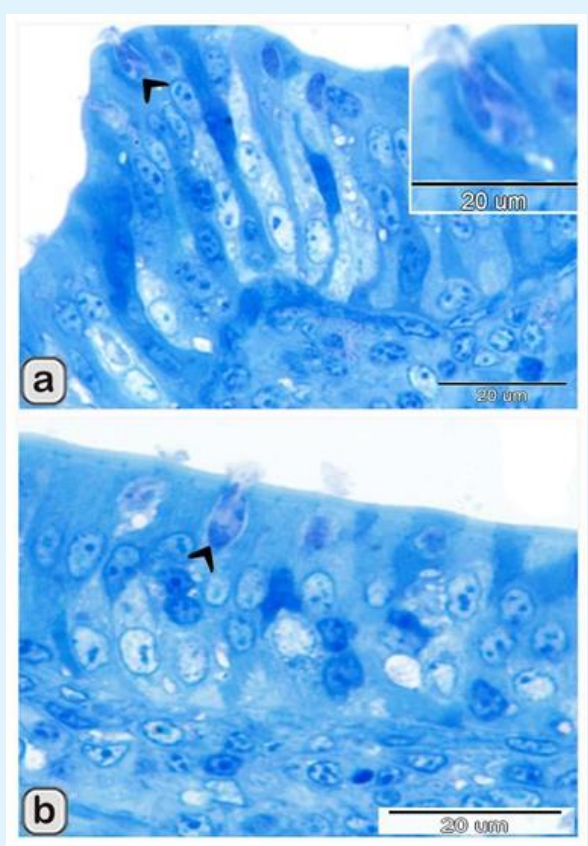

Figure 6: a \& b Photomicrograph of a semithin section of the middle part of the colon stained by toluidine blue showing the rodlet cell (arrowhead) within the lining mucosal layer.

\section{Discussion}

The current detected for the first-time localization of the rodlet cells in in the large intestine of examined male goose. Rodlet cells identification was performed using semithin sections and TEM. The study also described differential stages of rodlet cells in different layer of geese colon. In the current study, geese rodlet cells had the typical features of fish rodlet cells [2] that they exhibit cell polarity with wide basal portion and narrow apical end. They had typical rodlet granules that contained an electron lucent matrix and a central electron dens core. Geese rodlet cells had also the unique feature of rodlet cell membrane, which was supported by a thick fibrous capsule at the cytoplasmic aspect.

According to the present electron microscopic observations, the preculture and rupture stages of the rodlet cells of the examined male goose were observed within the epithelium while the transitional stage was demonstrated within the lamina propria. Various stages granules of maturation dominated the transitional stage, the pre-ruptured stage was pear shaped with widened basal part and tapered apical end, which moved toward 
the apical portion of the villi and the rupture stage, extrude the whole content into the epithelial surface. Stages of rodlet cell differentiation and maturation have been previously described the olfactory organ of the Ruby shark [2]. Geese rodlet cells exhibited similar differential sequences and features. Several functional implications have been proposed for rodlet cells in aquatic life. They serve in osmoregulation [5], sensory function [6], immune defense $[7,8]$. We suggested that rodlet cells are likely to be as part of the immune system of the geese colon. Enteric rodlet cells were probably serve in defensive mechanism against the aquatic environment.

In conclusion, the current study for the first time provided an evidence for existence of the enteric rodlet cells in the aquatic bird. Future studies should consider localization of rodlet cells in different organs of aquatic birds.

\section{References}

1. Ostrander GK (2000) The Laboratory Fish. Elsevier: 288.

2. Abd-Elhafeez HH, Soliman SA (2016) Origin of Rodlet Cells and Mapping Their Distribution in Ruby-Red-Fin Shark (Rainbow Shark) Epalzeorhynchos frenatum (Teleostei: Cyprinidae): Light, Immunohistochemistry and Ultrastructure Study. J Cytol Histol 7: 435.

3. Mazon AF, Huising MO, Taverne-Thiele AJ, Bastiaans J, Verburg-van Kemenade BM (2007) The first appearance of Rodlet cells in carp (Cyprinus carpio L.) ontogeny and their possible roles during stress and parasite infection. Fish Shellfish Immunol 22(12): 27-37.

4. Rideout RM, Smith SA, Morgan MJ (2015) Highdensity aggregations of rodlet cells in the gonads of Greenland halibut Reinhardtius hippoglossoides, a deep-water marine flatfish. J Fish Biol 86(5): 16301637.

5. Giari L, Manera M, Simoni E, Dezfuli BS (2006) Changes to chloride and rodlet cells in gills, kidney and intestine of Dicentrarchus labrax (L.) exposed to reduced salinities. Journal of Fish Biology 69(2): 590600 .

6. Dezfuli BS, Capuano S, Simoni E, Previati M, Giari L (2007) Rodlet cells and the sensory systems in zebrafish (Danio rerio). Anat Rec (Hoboken) 290(4): 367-374.

7. Reite OB, Evensen O (2006) Inflammatory cells of teleostean fish: a review focusing on mast cells/eosinophilic granule cells and rodlet cells. Fish Shellfish 212 Immunol 20(2): 192-208.

8. Matisz CE, Goater CP, Bray D (2010) Density and maturation of rodlet cells in brain tissue of fathead minnows (Pimephales promelas) exposed to trematode cercariae. Int J Parasitol 40(3): 307-312.

9. Reynolds ES (1963) The use of lead citrate at high pH as an electron-opaque stain in electron microscopy. J Cell Biol 17: 208-221. 